\title{
Use of a Scaffolded Case Study Assignment to Enhance Students' Scientific Literacy Skills in Undergraduate Nutritional Science Education: Comparison between Traditional Lecture and Distance Education Course Formats
}

\author{
Jennifer M. Monk ${ }^{1}$ \& Genevieve Newton ${ }^{1}$ \\ ${ }^{1}$ Department of Human Health and Nutritional Sciences, University of Guelph, Guelph ON, Canada, N1G 2W1. \\ Correspondence: Dr. Jennifer M. Monk, Department of Human Health and Nutritional Sciences, Animal Science and \\ Nutrition Building, Room 305, University of Guelph, Guelph, Ontario, Canada, N1G 2W1
}

Received: February 22, 2018

Accepted: March 15, 2018

Online Published: March 22, 2018

doi:10.5430/ijhe.v7n2p95

URL: https://doi.org/10.5430/ijhe.v7n2p95

\begin{abstract}
Abbreviations: CBL, case-based learning; DA, deep approach; DE, distance education; LEC, lecture; R-SPQ-2F, Revised Two-Factor Study Process Questionnaire 2; SA, surface approach; SL, scientific literacy

Abstract

We investigated whether the implementation of a scaffolded case study assignment could increase student perceptions of their scientific literacy (SL) skills in a third year Nutritional Science course. The change in students' SL perceptions were assessed by the completion of two surveys (administered at the start and end of the semester) consisting of questions probing a range of SL criteria relevant to undergraduate students. Additionally, we determined if the change in student perceived SL over the semester i) was related to their learning approach (i.e. deep versus surface approaches), as assessed by the Revised Two-Factor Study Process Questionnaire-2 (R-SPQ-2F), and ii) differed between course format, that is, in-class traditional lecture (LEC) and online distance education (DE). The LEC students $(n=179)$ showed improvements in all ten SL outcomes assessed over the course of the semester, whereas the DE students $(n=71)$ showed improvements in only six of the ten parameters assessed, however, the DE course started with a higher assessment of baseline SL capabilities. Additionally, the overall change in perceived SL capabilities was not associated with learning approach (i.e. surface or deep) in either class format. These data demonstrate that case-based learning assignments can promote students perceived SL capabilities in both traditional lecture and distance education course formats.
\end{abstract}

Keywords: scientific literacy, case-based learning, nutrition, undergraduate education, distance education, traditional lecture, pedagogy

\section{Introduction}

Typical expectations upon completion of undergraduate degrees in nutritional science, and more broadly in biological sciences, require graduates to exhibit the ability to work collaboratively and possess critical thinking and problem-solving skills, thereby requiring undergraduate teaching strategies that reflect and maximize these competencies while concomitantly solidifying the requisite knowledge base (Newton, Bettger, Buchholz, Kulak, \& Racey, 2015). Case-based learning (CBL) is a type of educational strategy that has been shown to promote the development of the aforementioned skills in undergraduate nutrition education (Davies, 2004; Harman et al., 2014; Johnson, Herd, Andrewartha, Jones, \& Malcolm, 2002), and therefore, requires a higher level of student engagement that is commonly associated with a deep learning approach (Biggs, Kember, \& Leung, 2001; Ramsden, 1984; Tiwari et al., 2005). CBL places student learning in an "authentic" environment by providing an inquiry-based strategy that uses clinical cases to draw a connection to real-life scenarios (Hutchings, 1993), thereby teaching course content while helping students experience decision-making and planning roles typically encountered in the workplace (Hartfield, 2010). Typically CBL presents material on a need-to-know basis, allowing students to become researchers and gather further information to solve the case, identify key concepts, integrate content, and make informed assessments to determine the best solutions to a problem (i.e. the presented case) (Savery, 2006), all of which are skills that translate well beyond the classroom (Newton et al., 2015) and therefore, require and/or build scientific literacy (SL) capabilities. 
SL is recognized as a critical component of science education, however, it is a generalized term whose definition has no clear consensus [reviewed elsewhere (De Boer, 2000; Laugksch, 2000; Norris \& Phillips, 2003)]. Despite the lack of a unifying definition, important components of SL comprise (but are not limited to) criteria such as i) the ability to distinguish between scientific and non-scientific sources (National Research Council, 1996; Council of Ministers of Education, 1997; Mayer, 1997), ii) independence in learning science (Sutman, 1996), iii) the ability to read and understand scientific literature (National Research Council, 1996; De Boer, 2000; Millar \& Osborne, 1998), iv) to interpret and integrate scientific reports, tables, graphs, drawings and diagrams (Anderson, 1999; Phillips, 2002), v) the ability to use scientific knowledge in problem solving (American Association for the Advancement of Science, 1993; National Research Council, 1996), and vi) the ability to think critically and evaluate the conclusions contained within scientific literature (De Boer, 2000; Korpan, Bisanz, Bisanz, \& Henderson, 1997; Shamos, 1995), as reviewed elsewhere (Norris \& Phillips, 2003). Therefore, literacy in the fundamental sense (i.e., reading and writing) (Norris \& Phillips, 2003), in addition to the acquisition, interpretation and integration of new knowledge or information are central to SL.

In contrast to in-class traditional lectures (LEC), students in distance education (DE) courses do not attend classes in person at regularly scheduled times, but instead have the flexibility to learn course content in a place and time of their own choosing and communication between teachers and students is on their own schedule by electronic means (Ekmekci, 2015; Hassenburg, 2009). Thus, the advantages of DE includes the enhanced access to education that might be limited to some students, such as those with disabilities who are unable to attend a physical campus or those in rural areas (Hassenburg, 2009). Additionally, the flexibility and convenience of DE allows for students to engage in their studies at personalized times rather than during pre-scheduled lectures, thereby better accommodating the needs of students who are returning to post-secondary education and/or balancing their academic studies with other commitments (Ekmekci, 2015; Hassenburg, 2009). Conversely, some disadvantages of DE can stem from the separation of the action of teaching and the reaction of learning, as instructors responsiveness to students needs can be delayed or compromised in DE courses versus traditional lecture (Hassenburg, 2009), although arguably this can be overcome by instructors that are flexible and place a priority on student communication, which influences students perceptions of DE courses (Salisbury, Pearson, Miller, \& Marett, 2002). Additionally, directing student discussions and communication online can be more challenging and different compared to a face to face dialogue, and the onus falls on the instructor to create a virtual classroom and encourage students to regularly check into and engage in the online discussions to better facilitate student learning. From the student perspective, since DE course content may be reviewed and completed at the students learning pace, and since the majority of the course is unsupervised (including online quizzes and exams in some cases), success in DE requires self-motivation and self-control. Not all students will have fully developed or possess these traits, thereby making DE course formats less ideal for all students, some of whom benefit from the structure of traditional lecture and the motivation and/or direction from the presence of an authoritative figure versus when left to their own self-efficacy (Hassenburg, 2009; Schunk, 1991). Therefore, it is conceivable that students who prefer DE over traditional lecture course formats may be more self-directed and exhibit a different approach to learning, namely a preference for surface versus deep learning strategies which describe the way students engage in a given learning task/activity aimed at surface memorization or deeper understanding of a concept (Biggs et al., 2001). Interestingly, the use of problem-based learning has been shown to promote deeper learning approaches (Newble \& Clark, 1986).

Therefore, in this study a scaffolded case study assignment was developed and utilized in a third year undergraduate nutrition course with the intended means of promoting the development of students' SL skills. The following research questions were investigated:

1. Does a scaffolded case study assignment in undergraduate nutrition education increase students' perceptions of their SL skills?

2. Is the change in students SL skills related to their learning approach (i.e. deep versus surface learning approaches)?

3. Is there a difference in students' perceptions of their SL skills or their learning approach between two distinct class formats, specifically the LEC versus DE formats?

\section{Methods}

\subsection{Participants}

Subjects were enrolled in Fundamentals of Nutrition (NUTR*3210) at the University of Guelph in either the face-to-face traditional lecture (LEC) or online distance education (DE) course formats in the Fall 2016 and Winter 
2017 semesters, respectively. In both course formats the content for each unit utilized the same course notes and the assessment of the students was similar, consisting of a midterm and final exam and the inclusion of a novel case-study group assignment ( $\mathrm{n}=4$ students per group) that was worth $10 \%$ of their final grade. All students registered in either course format were invited to complete a survey regarding their perceptions of their SL skills. The surveys were completed twice, once at the beginning of the semester (i.e. during week one of classes) and a second time at the end of the semester (i.e. during week 12 of classes, after completion of the scaffolded case study assignment). Within the LEC course $\mathrm{n}=179$ out of 208 registered students completed both surveys (86\% participation), whereas in the DE course $\mathrm{n}=71$ out of 124 students completed both surveys (57\% participation) and were included in the analyses presented in this paper. Students were awarded a $1 \%$ bonus mark on either the midterm or final exam for completion of the first and second surveys, respectively, although they could abstain from completing the surveys and alternatively complete a short written assignment to earn the bonus mark. The semester of study distribution (i.e. semester number out of an eight semester undergraduate program) of students enrolled in the DE and LEC formats of NUTR*3210 is shown in Figure 1. In the LEC course, the majority of students (51\%) were enrolled in the $5^{\text {th }}$ semester of their respective undergraduate programs, whereas in the DE course the majority of students were enrolled in the $4^{\text {th }}$ semester of their respective undergraduate programs. All participating students gave informed consent and this study was approved by the Research Ethics Board of the University of Guelph (REB\#16JL018).
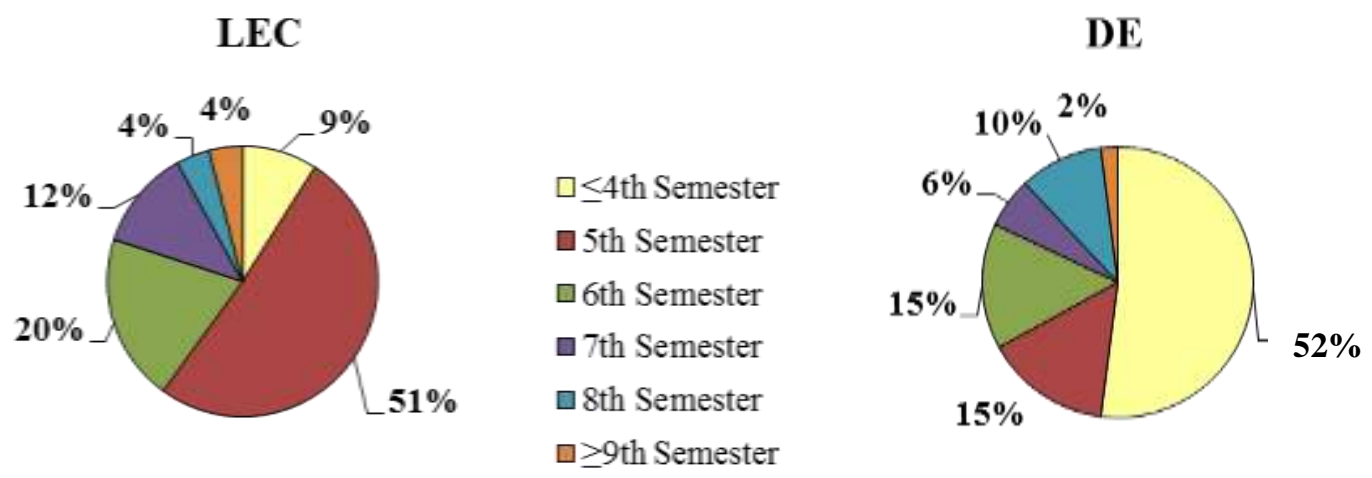

Figure 1. Distribution of students semester of study out of an eight semester undergraduate program at the time they were enrolled NUTR*3210 in either the LEC (fall 2016 semester) and DE (winter 2017 semester) course formats.

\subsection{Scaffolded Case Study Assignment}

Prior to the start of the course exemplar case studies were created that were associated with the course content in units 4 (Review of Intermediary Metabolism) and 7 (Protein). Each case study consisted of i) the case (i.e. the novel problem or situation) vignette, ii) learning objectives related to the case, iii) study questions that were rooted in the case learning objectives and intended to promote/aid in solving the case, and iv) paragraph style answers to the case study questions that were supported with citations from the scientific literature.

A scaffolded approach to case-based learning was utilized during the 12 week semester, which is outlined in Figure 2. In week one of the semester students were invited (by email) to complete the pre-assignment SL survey. In week two of the semester students were provided access to a video (generated by G.N.) with the accompanying text script of the video content that introduced them to the concept of case-based learning in science education and outlined the requirements of the NUTR $* 3210$ case study assignment. Students were also provided with an introduction to case-based learning through the required reading of "A Guide to Using Case-Based Learning Biochemistry Education" by Kalak \& Newton, 2014 (Kalak \& Newtion, 2014). In week four of the semester, the first case study exemplar (linked to the course content in unit 4: review of intermediary metabolism) was posted and discussed. In week seven of the semester, the second case study exemplar (linked to the course content in unit 7: protein) was posted and discussed. In week eight, students were randomly assigned to groups of four students and reminded to review the description of the case study assignment and the associated rubric which were provided to the class. In week nine, students were instructed to begin working on their case study assignment by first identifying the 5-10 learning outcomes related to the case study to be developed by each group. Subsequently, students were instructed to create a vignette that describes the novel case that they are creating with a reminder to review the assigned case-based learning references that were provided in week two of the semester to facilitate this process. In 
week 10, students were instructed to work collaboratively to identify and collect data in the form of tables and/or figures that will help provide a solution to their novel case. Additionally, students worked to translate the learning outcomes from week nine in to specific questions and solutions that relate to the case. In week 11, students were instructed to review and edit their case study and to prepare a final draft according to the formatting specifications outlined in week two when the requirements of the assignment were provided to students. In week 12, students submitted their final case study group assignment for grading by the teaching assistant. Additionally, in week 12, students were invited (by email) to complete the post-assignment survey that consisted of two parts i) the SL questions (identical to the pre-assignment survey completed in week one of the semester) and ii) the Revised Student Process Questionnaire with Two Factors (R-SPQ-2F) (Biggs et al., 2001).

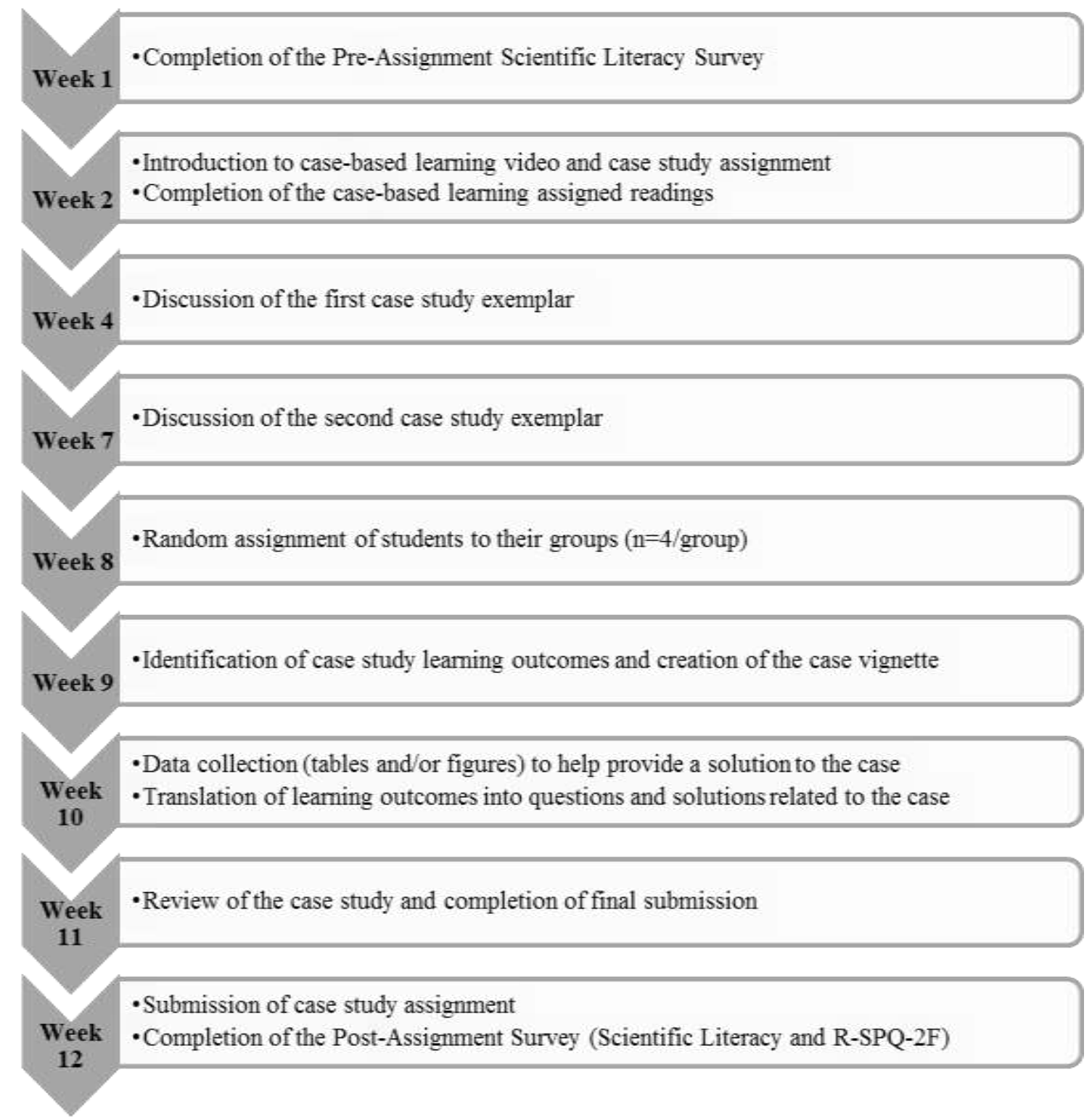

Figure 2. Outline of the scaffolded case study assignment activities throughout the 12 week semester.

\subsection{SL Surveys}

At the start of the semester (week one) students completed a pre-assignment (i.e. prior to introduction to case-based learning) survey regarding their perceived SL skills/competency, which is a non-validated survey generated by the researchers consisting of 10 questions that address a spectrum of SL-based skills/abilities (shown in Table 1). For each statement, students indicated their perceived level of confidence in their abilities using a scale of 0 through 10 , that progressed as follows: 0 "strongly disagree", 1-2 "disagree", 3-4 "somewhat disagree", 5 "neither agree nor disagree", 6-7 "somewhat agree", 8-9 "agree" and 10 "strongly agree". At the end of the semester (week 12) 
students completed a post-assignment survey that consisted of two parts: i) a re-assessment of their perceived SL skills (identical to the pre-assignment survey), and ii) the R-SPQ-2F, which is designed to measure whether students take a deep or surface approach to learning (Biggs et al., 2001). Initially created as the Study Process Questionnaire, this revised version consists of 20 questions, with 10 items representing each learning approach, namely deep and surface (Biggs et al., 2001). Although this questionnaire also includes four subscales that describe motive and strategy, it has been shown that the R-SPQ-2F best describes the two factors of deep and surface learning approaches (Justicia, Pichardo, Cano, Berbén, \& De la Fuente, 2008), and therefore, only these variables were considered in this study.

For the SL survey responses, within each course (LEC and DE), scores from the pre-assignment and post-assignment time points were compared for each student and the overall change for each SL parameter over the course of the semester was assessed. Subsequently, the changes in students' SL perceptions were compared between the course formats, namely LEC versus DE, to determine if there was a difference between course formats. Students had to provide informed consent prior to the start of both the pre- and post-assignment surveys, which were distributed to all enrolled students in each class using a private invitation link to the online survey, which was administered using the Qualitrics Insight Platform (Provo, UT, USA).

\subsection{Statistics}

All data were analyzed using Graphpad Prism 5.0 (GraphPad Software, Inc., La Jolla, CA, USA) and the $P$-value was set at less than 0.05. Paired t-tests were performed to determine the relationship between mean pre-assignment and mean post-assignment SL for each the ten survey questions as well as the overall score (the sum of the ten questions) within each course format. The pre-assignment and post-assignment survey responses to each question were compared between course formats using an unpaired t-test. The change in students' perceptions of SL capabilities (pre- versus post-assignment) for each survey question, as well as the overall score change, was then compared between course formats (i.e. LEC versus DE) using an unpaired t-test. Linear regression was conducted to determine the association between the mean change in overall SL perceptions and i) deep learning approach score, and ii) surface learning approach score in both course formats (DE and LEC). The assumption of normality was assessed using the Shapiro-Wilk test.

Table 1. Scientific literacy survey questions (answered using a scale of 1-10, where 1 is the lowest level of agreement and 10 being the highest level of agreement).

\begin{tabular}{ll}
\hline Question Number & Survey Question \\
\hline $\mathbf{1}$ & I feel confident in my ability to distinguish between primary and secondary sources of \\
& scientific literature. \\
I feel confident in my ability to effectively search for and find scientific literature using \\
catalogued databases (e.g. www.pubmed.com). \\
I feel confident in my ability to evaluate the relevance of information presented in scientific \\
literature in relation to a given topic or research question \\
I feel confident in my ability to extract relevant information from scientific literature to \\
support a given topic or research question. \\
I feel confident in my ability to integrate information collected from multiple sources of \\
scientific literature to address a given topic or research question. \\
$\mathbf{6}$ & I feel confident in my ability to interpret data from scientific literature that is presented in the \\
& form of table. \\
& I feel confident in my ability to interpret data from scientific literature that is presented in the \\
& form of a figure (bar graph, line graph, pie chart, etc.). \\
$\mathbf{9}$ & I feel confident in my ability to use information obtained from scientific literature to address \\
& an unfamiliar problem. \\
& I feel confident in my ability to use information obtained from scientific literature to identify \\
& a novel problem or research question. \\
& I feel confident in my ability to translate complex knowledge obtained from scientific \\
& literature into clear and understandable terms.
\end{tabular}




\section{Results}

\subsection{DE Students SL Perceptions Pre- and Post-Case Study Assignment}

The results from the pre-assignment and post-assignment surveys for students' perceptions of their SL competency along with the mean change pre versus post survey for both course formats (DE and LEC) are presented in Table 2. In the DE course, the mean change in students' SL perceptions between the pre-assignment and post-assignment survey was significantly increased in four of the ten SL parameters assessed. These improved SL outcomes included skills such as distinguishing between primary and secondary sources of scientific literature (Question 1), their utilizing information collected from the scientific literature to address an unfamiliar problem and to identify a novel problem or research question (Questions 8 and 9, respectively) and to translate this new information or knowledge into clear and understandable terms (Question 10). Although non-significant increases in SL perceptions were observed in response to the survey (Questions 2, 3 and 6), some SL parameters were unchanged, particularly SL capabilities centered on extraction of relevant supporting information, integration of information collected from multiple sources and interpretation of data presented in graphical form (Questions 4, 5 and 7). Importantly, the overall change (sum of all SL outcomes combined) assessed in the pre- and post-assignment surveys was significantly increased.

\subsection{LEC Students SL Perceptions Pre- and Post-Case Study Assignment}

In the LEC course the mean change in students SL perceptions between the pre-assignment and post-assignment survey were significantly increased for all ten parameters assessed (Table 2). Therefore, not unexpectedly, the overall change (sum of all SL outcomes) between the pre- and post-assignment survey was also significantly increased in the LEC student cohort.

\subsection{Comparison between Students' SL Perceptions in the DE and LEC Course Formats}

Comparison between course formats (i.e. DE versus LEC) of the mean change for each SL parameter assessed between the pre-assignment and post-assignment surveys are presented in Table 2. The mean change in students perceived SL capabilities over the course of the semester (pre- versus post-assignment survey outcomes) differed between course formats for eight of the ten parameters assessed, wherein the LEC students exhibited more improvement from their respective pre-assignment survey responses compared to the DE students. Interestingly, the mean change in perceived SL capabilities did not differ between DE and LEC students for two SL parameters assessed, which included confidence in searching and finding scientific literature using catalogued databases (Question 2) and interpreting tabular data (Question 6).

Overall, students in both course formats exhibited improvements in SL based on the combined score of all ten SL parameters (pre- versus post-assignment survey), however, the students in the LEC course showed a greater overall increase in their SL score compared to DE (LEC: +6.80 versus DE: $+2.25, P=0.0002$ ). Importantly, the mean value for the DE students baseline pre-assignment survey responses for each of the ten SL parameters started at a higher score out of 10 compared to the LEC students, thereby demonstrating a greater degree of SL confidence at the outset of the semester. Despite this, at the end of the semester comparison of the post-assignment survey responses between course formats revealed that the LEC and DE students perceived SL capabilities were equivalent and did not differ from each other in nine of the ten SL parameters assessed or in their overall score (Table 2). In the post-assignment survey LEC students had a lower degree of SL confidence in their ability to search for scientific information using catalogued databases (Question 2) compared to DE. Thus, overall, the LEC students started with lower perceived SL capabilities compared to DE, but students in both course formats exhibited increased SL confidence over the course of the semester and ended within similar degrees of SL confidence. 
Table 2. Pre- and Post-Assignment Scientific Literacy Survey Scores ${ }^{1}$

\begin{tabular}{|c|c|c|c|c|c|c|c|}
\hline \multirow[b]{2}{*}{$\begin{array}{l}\text { Survey } \\
\text { Question } \\
\text { (score/10) }\end{array}$} & \multicolumn{3}{|l|}{ DE } & \multicolumn{3}{|l|}{ LEC } & \multirow[b]{2}{*}{$\begin{array}{l}\text { Change } \\
\text { DE vs. } \\
\text { LEC } \\
(P \text {-value })\end{array}$} \\
\hline & $\begin{array}{l}\text { Mean } \\
\text { Pre-Assignment } \\
\text { Score } \\
( \pm \text { SEM })\end{array}$ & $\begin{array}{l}\text { Mean } \\
\text { Post-Assignment } \\
\text { Score } \\
\quad( \pm \text { SEM })\end{array}$ & $\begin{array}{l}\text { Mean } \\
\text { Change: } \\
\text { Pre vs. } \\
\text { Post }\end{array}$ & $\begin{array}{l}\text { Mean } \\
\text { Pre-Assignment } \\
\text { Score } \\
( \pm \text { SEM) }\end{array}$ & $\begin{array}{l}\text { Mean } \\
\text { Post-Assignment } \\
\text { Score } \\
\quad( \pm \text { SEM) }\end{array}$ & $\begin{array}{l}\text { Mean } \\
\text { Change: } \\
\text { Pre vs. } \\
\text { Post }\end{array}$ & \\
\hline 1 & $7.96(0.21)$ & $8.35(0.17)$ & $+0.39 *$ & $7.49(0.13)^{\#}$ & $8.20(0.13)$ & $+0.71 *$ & 0.061 \\
\hline 2 & $8.37(0.15)$ & $8.61(0.15)$ & +0.24 & $7.72(0.12)^{\#}$ & $8.13(0.11)^{\ddagger}$ & $+0.41 *$ & 0.210 \\
\hline 3 & $7.86(0.14)$ & $8.09(0.16)$ & +0.23 & $7.27(0.10)^{\#}$ & $7.91(0.10)$ & $+0.64 *$ & 0.088 \\
\hline 4 & $8.00(0.13)$ & $8.00(0.16)$ & 0.00 & $7.47(0.10)^{\#}$ & $7.95(0.10)$ & $+0.48^{*}$ & 0.022 \\
\hline 5 & $7.93(0.15)$ & $7.90(0.19)$ & -0.03 & $7.33(0.11)^{\#}$ & $7.87(0.10)$ & $+0.54 *$ & 0.008 \\
\hline 6 & $7.60(0.16)$ & $7.81(0.19)$ & +0.21 & $7.04(0.12)^{\#}$ & $7.55(0.11)$ & $+0.51 *$ & 0.391 \\
\hline 7 & $7.71(0.17)$ & $7.61(0.20)$ & -0.10 & $7.07(0.12)^{\#}$ & $7.67(0.11)$ & $+0.60 *$ & 0.005 \\
\hline 8 & $6.94(0.19)$ & $7.37(0.18)$ & $+0.43 *$ & $6.40(0.12)^{\#}$ & $7.34(0.11)$ & $+0.94 *$ & 0.003 \\
\hline 9 & $6.94(0.22)$ & $7.44(0.19)$ & $+0.50 *$ & $6.45(0.12)^{\#}$ & $7.46(0.11)$ & $+1.01 *$ & 0.023 \\
\hline 10 & $7.07(0.19)$ & $7.45(0.20)$ & $+0.38^{*}$ & $6.52(0.12)^{\#}$ & $7.48(0.10)$ & $+0.96^{*}$ & 0.003 \\
\hline $\begin{array}{l}\text { Overall } \\
\text { Score } \\
(/ 100)\end{array}$ & $76.38(1.33)$ & $78.63(1.36)$ & $+2.25^{*}$ & $70.76(0.84)^{\#}$ & $77.56(0.81)$ & $+6.80 *$ & 0.0002 \\
\hline
\end{tabular}

${ }^{1}$ Data are presented as means (SEM). A maximum score of 10 was possible for each of the 10 questions that constitute the scientific literacy survey, and a maximum overall score of 100 was possible for both the pre-and post-assignment scientific literacy surveys.

(*) Denotes statistically significant differences $(P \leq 0.05)$ between the mean change in SL (post-assignment survey pre-assignment survey score) within each class format (DE, online distance education; LEC, traditional face-to-face lecture).

(\#) Denotes statistically significant differences $(P \leq 0.05)$ in the pre-assignment SL score between course formats.

(\$) Denotes statistically significant differences $(P \leq 0.05)$ in the post-assignment SL score between course formats.

3.4 Associations between the Overall Change SL Scores and Learning Approach in the DE and LEC Course Formats

In the DE course format there was no association between the overall change in SL score (sum of all SL parameters) and approach to learning, either deep approach (DA: $P=0.992$, Figure 3A) or surface approach (SA: $P=0.712$, Figure 3B). Similarly, in the LEC course format, there was also no association between the overall change in students' SL score and either learning approach score (DA: $P=0.164$ and SA: $P=0.223$ ) as shown in Figure 3C and Figure 3D, respectively. 
3A)

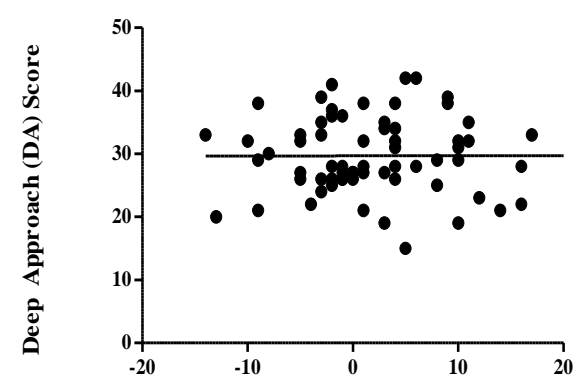

Overall Change in Scientific Literacy Score (Pre vs Post Survey)

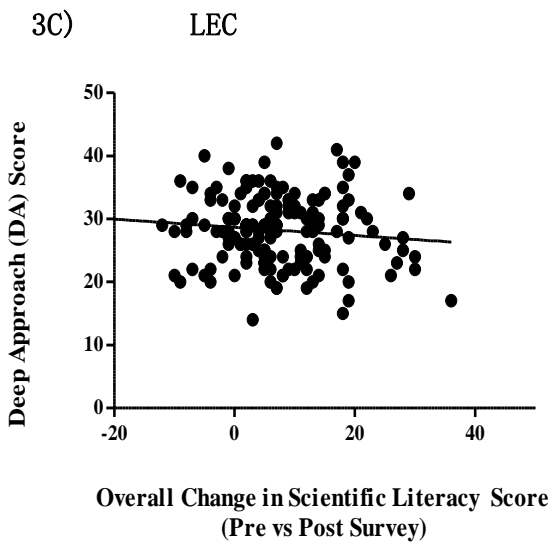

3B) $\quad \mathrm{DE}$

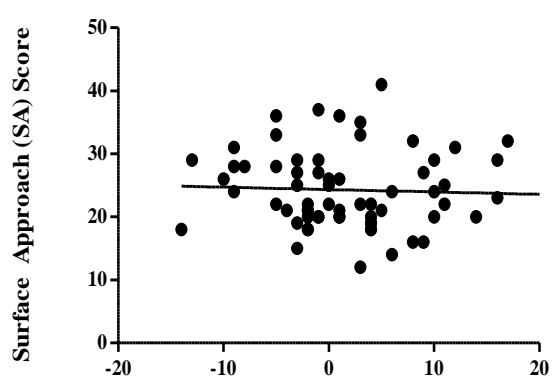

Overall Change in Scientific Literacy Score (Pre vs Post Survey)

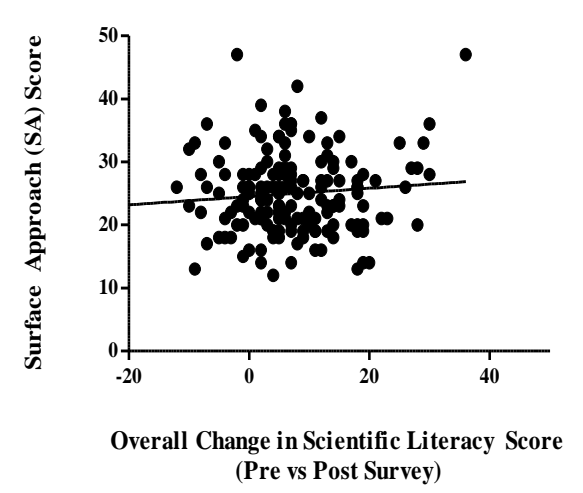

Figure 3. Scatterplot depicting the relationship between the change in overall SL score (pre versus post survey) and learning approach (deep approach, DA and surface approach, SA) in both the DE and LEC course formats. A) DA learning approach in the DE course $\left(\mathrm{R}^{2}\right.$ linear $\left.=0.0002, P=0.992\right)$, trend line is represented by the formula: overall change in SL score $=(0.001 \times$ deep approach score $)+29.710$. B) SA learning approach in the DE course $\left(\mathrm{R}^{2}\right.$ linear $=0.002, P=0.712)$, trend line is represented by the formula: overall change in SL score $=(-0.038 \mathrm{x}$ surface approach score $)+24.350$. C) DA learning approach in the LEC course $\left(\mathrm{R}^{2}\right.$ linear $\left.=0.012, P=0.164\right)$, trend line is represented by the formula: overall change in SL score $=(-0.065 \mathrm{x}$ deep approach score $)+28.690$. B) SA learning approach in the DE course $\left(\mathrm{R}^{2}\right.$ linear $\left.=0.009, P=0.233\right)$, trend line is represented by the formula: overall change in SL score $=$ (0.066 x surface approach score) +24.520 .

\section{Discussion}

The aim of the present study was to utilize a scaffolded case study assignment in both the traditional lecture (LEC) and distance education (DE) formats of a third year level undergraduate nutrition course as a means to foster students perceived SL skills as assessed by surveys administered at both the start and end of the 12 week academic semester. Overall, students in both course formats exhibited improvements in their perceived SL capabilities following completion of the scaffolded case-based learning assignment that included an improved SL aggregate score of all SL components assessed by the survey questions as well as individual SL components targeting specific clusters of SL skills, although there were some differences noted between the course delivery formats. Additionally, the overall change in students reported SL skills were correlated with their approach to learning (i.e. deep versus surface learning approaches) and the results were compared between two distinct course delivery formats (DE versus LEC).

Despite overall improvements in students' perception of SL capabilities in both course formats assessed, there were important differences that were apparent between the course delivery formats. Specifically, LEC students showed 
the largest increase in the overall SL score (sum of all SL parameters assessed) compared to DE, and LEC students showed improvements in all ten SL parameters assessed by the survey questions (pre- versus post-assignment surveys), whereas the DE students showed improvements in only four of the ten parameters assessed. In particular, the four SL parameters that were improved in DE students included confidence in distinguishing between primary and secondary literature sources, utilizing the accessed information to address and identify unfamiliar problems and translate the information into clear and understandable terms. Importantly, the baseline pre-assignment survey conducted at the start of the semester demonstrated that students in the DE course exhibited higher perceptions of their SL capabilities in all ten parameters assessed compared to the LEC students, indicating that the cohort of students in the DE course started the semester with greater SL confidence, which was further improved over the course of the academic semester and through the completion of the case-based learning assignment. Therefore, although the magnitude of the DE students' perceived increased SL capabilities were lower versus LEC, the DE cohort of students already exhibited higher SL capabilities, which were further enhanced in four of the ten SL parameters assessed in the post-assignment survey. Therefore, not unexpectedly, the LEC students who started the semester with lower baseline perceptions of their SL capabilities demonstrated improvements in each of the ten SL parameters assessed (pre- versus post-assignment survey). Regardless of students baseline confidence in their SL capabilities in the pre-assignment survey, at the end of the academic semester and completion of the case-based learning assignment students in both the DE and LEC course formats exhibited equivalent SL capabilities as assessed by their post-assignment survey scores, with the exception of confidence to access information from catalogued databases, which remained lower in LEC students versus DE. The post-assignment overall SL scores did not differ between students in either course format, indicating that LEC students who started with lower SL confidence had caught up to their peers in the DE course.

Proximity to previous learning experiences may provide an explanation as to why students in the DE course started with higher baseline confidence in their SL capabilities (i.e. in the pre-assignment survey) compared to students in the LEC course. First, the LEC course was offered in the fall semester, wherein students following the traditional academic program calendar would be in the first week of classes at the time of the pre-assignment survey having just returned to classes following the summer semester break. During this transition time (following the semester long gap in their learning/academic experiences and returning to classes and the upcoming semester of study after a four month break in their academic program) students may have experienced lower confidence and perceptions of the SL capabilities when asked to provide a self-assessment. Conversely, in the DE course there was a minimal gap in students learning/academic experience, as the course was offered in the winter semester, wherein students following the academic program calendar would have just completed the fall semester of classes prior to the start of the winter semester. Therefore, students in the DE course could have exhibited greater baseline (i.e. pre-assignment) SL confidence by drawing from recent academic experience, whereas students in the LEC course did not have as recent an academic experience to draw from when providing their SL self-assessment. To avoid this potential confounding factor studies comparing course delivery formats should be offered within the same academic semester.

Proximity to previous academic experiences may have underlined the difference in baseline SL confidence between the DE and LEC students in another way. At the University of Guelph the first year biology curriculum has been recently redesigned with an emphasis on evidence-based approaches that encourage higher-order learning, deeper levels of cognition and development of skills and attributes that are important in the study of biology (Husband et al., 2015; Murrant et al., 2015). Thus, within this newly implemented curriculum there is a strong focus on the development of SL through the use of problem-based learning introduced to all first year biology students from the outset of their post-secondary education (Husband et al., 2015; Murrant et al., 2015). Proximity to this intensive SL promoting problem-based learning academic experience may have influenced students' perceptions of their baseline SL capabilities. Specifically, the majority of students $(71 \%)$ in the LEC course were enrolled in either semester five or six of their eight semester program of study (equivalent to a third year student) and overall $91 \%$ of LEC students were in enrolled in semester 5 or higher versus the $9 \%$ of students that were enrolled in semester 4 or lower, and therefore, the proximity to the first year biology problem-based learning experience was less recent for the majority of LEC students. Conversely, the majority of students in the DE course (52\%) were enrolled in semester four or lower in their eight semester programs of study (equivalent to a second year student), and therefore, the majority of DE students exhibited a closer proximity to the first year biology problem-based learning experience (Husband et al., 2015; Murrant et al., 2015), which may help to explain the discrepancy in baseline SL confidence between the DE and LEC students.

A secondary objective of this study was to determine if the overall change in students' perceived SL skills over the course of the 12 week semester was related to their approach to learning, as determined by the R-SPQ-2F. It was 
hypothesized that students who utilize a surface approach to learning would be correlated with lower perceived SL skills, whereas students who utilize a deeper approach to learning would be directly correlated with the increased overall change in perceived SL skills. However, our findings revealed that the overall change in students' perceived SL capabilities was not associated with either a surface or deep learning approach.

Based on the study design implemented wherein all students registered in either the LEC or DE course formats were invited to complete the SL surveys, the intended outcome was a larger sample size of study participants and enhanced statistical power of our analyses; however, the limitation is the lack of a control group that did not participate in the group case study assignment and only engaged in the lecture content of the course. Therefore, the ability to draw conclusions regarding cause and effect of the group case study assignment is limited. Furthermore, the enhanced student perceptions of SL capabilities observed over the course of the semester cannot be attributed exclusively to the case study assignment as other concurrent learning experiences in other courses during the semester could also have contributed to the students' perceived SL. Despite the effort to maximize the sample size utilized in our study, there were differences between the DE and LEC courses, such that in the DE course only 71 students (57\% participation) gave informed consent and completed both online surveys, whereas in the LEC course there was $86 \%$ participation and the final sample size consisted of 179 students. This discrepancy between course formats may have limited the statistical power of the analyses or may not be as representative of the larger undergraduate student population. Moreover, future work would benefit from a larger sample size and the inclusion of a cohort of students enrolled in the same course who does not participate in the group case-based learning assignment in order to draw more reliable conclusions.

Collectively, the results from the current study support the interpretation that CBL can promote student perceptions of SL capabilities, as assessed utilizing SL outputs that reflect previously identified important components of SL including the acquisition, understanding, interpretation, evaluation and application of scientific literature to solve problems (American Association for the Advancement of Science, 1993; National Research Council, 1996; Anderson, 1999; Council of Ministers of Education, 1997; De Boer, 2000; Korpan et al., 1997; Mayer, 1997; Millar \& Osborne, 1998; Norris \& Phillips, 2003; Phillips, 2002; Shamos, 1995). Furthermore, the findings of this study add enhanced SL capabilities to the growing list of benefits associated with CBL in nutritional science education including increased student motivation and performance, the promotion of critical thinking skills and the integration of concepts to promote student perceptions of "the big picture" (Davies, 2004; Harman et al., 2014; Johnson et al., 2002). Further study is required to directly measure SL capabilities beyond student reported perceptions (as assessed by survey herein), however, the current study provides proof-of-concept that CBL approaches in nutrition education enhance undergraduate student SL.

\section{References}

American Association for the Advancement of Science. (1993). Benchmarks for science literacy. New York: Oxford University Press.

National Research Council. (1996). National Science Education Stadards. Washington, DC: The National Acadmies Press. http://doi.org/10.17226/4962

Anderson, C. W. (1999). Inscriptions and science learning. Journal of Research in Science Teaching, 36, 973-974. http://doi.org/10.1002/(SICI)1098-2736(199911)36:9<973::AID-TEA1>3.0.CO;2-C

Biggs, J., Kember, D., \& Leung, D. Y. P. (2001). The revised two-factor study process questionaire: R-SPQ-2F. British Journal of Educational Psychology, 71, 133-149. http://doi.org/10.1348/000709901158433

Council of Ministers of Education, C. C. (1997). Common framework of science learning outcomes K to 12. Toronto: Council of Ministers of Education, Canada.

Davies, M. (2004). The successful use of case studies in nutritional biochemistry. Georgia Journal of Science, 62(2), 79-86.

De Boer, G. E. (2000). Scientific Literacy: Another look at its historical and contemporary meanings and its relationship to science education reform. Journal of Research in Science Teaching, 37(6), 582-601. http://doi.org/ 10.1002/1098-2736(200008)37:6<582::AID-TEA5>3.0.CO;2-L

Ekmekci, E. (2015). Distance-education in foreign language teaching: evaluations from the perspectives of freshman students. Procedia - Social and Behavioral Sciences, 176, 390-397. https://doi.org/10.1016/j.sbspro.2015.01.487 
Harman, T., Betrand, B., Greer, A., Pettus, A., Jennings, J., Wall-Bassett, E., et al. (2014). Case-based learning facilitates critical thinking in undergraduate nutrition education: students describe the big picture. Journal of the Academy of Nutrition and Dietetics, 115(3), 378-388. https://doi.org/10.1016/j.jand.2014.09.003

Hartfield, P. (2010). Reinforcing constructivist teaching in advanced level biochemistry through the introduction of case-based learning activities. J Learn Des, 3, 20-31. http://dx.doi.org/10.5204/jld.v3i3.59

Hassenburg, A. (2009). Distance education versus the traditional classroom. Berkeley Scientific Journal, 13(1), 7-10.

Husband, B. C., Bettger, W. J., Murrant, C. L., Kirby, K., Wright, P. A., Newmaster, S. G., et al. (2015). Applying a linked-course model to foster inquiry and integration across large first-year courses. Canadian Journal of Higher Education, 45(4), 244-260.

Hutchings, P. (1993). Using cases to improve college teaching: A guid to more reflective practice. J Coll Sci Teach, 23(1), 221-229.

Johnson, E., Herd, S., Andrewartha, K., Jones, S., \& Malcolm, S. (2002). Introducing problem-based learning into a tradtional lecture course. Biochemistry and Molecular Biology Education, 30(2), 121-124. http://doi.org/ 10.1002/bmb.2002.494030020023

Justicia, F., Pichardo, M. C., Cano, F., Berbén, A. B. G., \& De la Fuente, J. (2008). The revised two-factor study process questionnaire (R-SPQ-2F): Exploratory and confirmatory factor analyses at item level. European Journal of Psychology of Education, 23(3), 355-372. https://doi.org/10.1007/BF03173004

Kalak, V., \& Newtion, G. (2014). A guide to using case-based learning in biochemistry education. Biochemistry and Molecular Biology Education, 42(6), 457-473. http://doi.org/ 10.1002/bmb.20823

Korpan, C. A., Bisanz, G. I., Bisanz, J., \& Henderson, J. M. (1997). Assessing literacy in science: Evaluation of scientific news briefs. Science Education, 81(5), 515-532. http://doi.org/ 10.1002/(SICI)1098-237X(199709)81:5<515::AID-SCE2>3.0.CO;2-D

Laugksch, R. C. (2000). Scientific literacy: a conceptual overview. Science Education, 84(1), 71-94. http://doi.org/ 10.1002/(SICI) 1098-237X(200001)84:1<71::AID-SCE6>3.0.CO;2-C

Mayer, V. J. (1997). Global science literacy: An earth system view. Journal of Research in Science Teaching, 34, 101-105. http://doi.org/ 10.1002/(SICI)1098-2736(199702)34:2<101::AID-TEA1>3.0.CO;2-X

Millar, R., \& Osborne, J. (1998). Beyond 2000: Science education for the future (the report of a seminar series funded by the Nuffield Foundation). London: King's College London.

Murrant, C. L., Dyck, D. J., Kirkland, J. B., Newton, G. S., Ritchie, K. L., Tishinsky, J. M., et al. (2015). A large, first-year, introductory, multi-sectional biological concepts of health course designed to develop skills and enhance deeper learning. Canadian Journal of Higher Education, 45(4), 42-62.

Newble, D., \& Clark, R. M. (1986). The approaches to learning of students in a traditional and in a problem-based medical school. Medical Education, 20, 267-273. http://doi.org/ 10.1111/j.1365-2923.1986.tb01365.x

Newton, G., Bettger, W., Buchholz, A., Kulak, V., \& Racey, M. (2015). Evidence-informed strategies for undergraduate nutrition education: a review. Appl Physiol Nutr Metab, 40(7), 652-661. http://doi.org/ 10.1139/apnm-2014-0368

Norris, S. P., \& Phillips, L. M. (2003). How literacy in its fundamental sense is central to scientific literacy. Science Education, 87(2), 224-240. http://doi.org/ 10.1002/sce.10066

Phillips, L. (2002). Making new and making do: Epistemological, normative and pragmatic bases of literacy. In O. D.R., D. Kamawar \& J. Brockmeier (Eds.), Lieracy and conceptions of language and mind (pp. 283-300). Cambridge: Cambridge University Press.

Ramsden, P. (1984). In F. Marton, D. Hounsell \& N. Entwistle (Eds.), The experience of learning (pp. 144-164). Edinburgh: Scottish Academic Press.

Salisbury, W. D., Pearson, R. A., Miller, D. W., \& Marett, L. K. (2002). The limits of information: A cautionary tale about one course delivery exeprience in the distance education environment. e-Service Journal, 1(2), 65-81. http://doi.org/10.2979/esj.2002.1.2.65

Savery, J. R. (2006). Overview of problem-based learning: definitions and distinctions. Interdis J Problem-based Learning, 1(1), 9-20. https://doi.org/10.7771/1541-5015.1002 
Schunk, D. H. (1991). Self efficacy and academic motivation. Educational Psychologist, 26(3), 207-231. https://doi.org/10.1207/s15326985ep2603\&4_2

Shamos, M. H. (1995). The myth of scientific literacy. New Brunswick, NJ: Rutgers University Press.

Sutman, F. X. (1996). Scientific literacy: a functional definition. Journal of Research in Science Teaching, 33, 459-460.

Tiwari, A., Lam, D., Yuen, K., Chan, R., Fung, T., \& Chan, S. (2005). Student learning in clincial nursing education: Perceptions of the relationship between assessment and learning. Nurse Education Today, 25, 299-308. https://doi.org/10.1016/j.nedt.2005.01.013 